$\S=$

\title{
Qualitative study of roles of religious leaders in promoting adolescent sexual reproductive health and rights in Iganga municipality Uganda
}

\author{
Nayebare Baturaine Barbara ${ }^{1}$, Omona Kizito $[\mathrm{PhD}]^{2 *}$ \\ ${ }^{I}$ MPH Student, Faculty of Health Sciences, Uganda Martyrs University \\ ${ }^{2}$ Lecturer, Faculty of Health Sciences, Uganda Martyrs University \\ *Corresponding author E-mail: komona@umu.ac.ug
}

\begin{abstract}
Introduction: Young people in adolescent stage are very vulnerable. Sexual and reproductive health choices they make as they transition from childhood to adulthood determine a lot about their well-being.

Objective: To assess the role of religious leaders in promoting adolescent sexual and reproductive health rights in Iganga Municipality.

Methodology: Qualitative phenomenological design was used. Sample of 30 participants (25religious leaders and 5adolescents) were interviewed. Data was collected using in-depth interviews, transcribed, coded and analyzed using thematic content analysis.

Results: Information shared by religious leaders to adolescents helped them to live responsible lives. Results also indicated that; religious leaders perceived promotion of ASRHR to imply elevation of sexual immorality. Religious leaders had both protective and preventive influences on promotion of ASRHR.

Conclusion: Religious leaders greatly contribute to promotion of ASRHR by enhancing information sharing. Dialogues, therefore, enhances their awareness about ASRHR and gives them confidence to address the matter with adolescents.
\end{abstract}

Keywords: Adolescent Sexual and Reproductive Health and Rights (ASRHR); Adolescents; Religious leaders.

\section{Introduction}

\subsection{Background of the study}

In the study, roles of religious leaders were studied to mean provision of leadership, facilitating dialogue, as well as information sharing, which will create a sense of understanding, ownership and capacity building of the religious leaders to promote/address ASRHR challenges.

The world's population is largely dominated by young people. In sub Saharan Africa, more than one third of the population are young people aged 10-24 years, with enormous numbers dwelling in developing countries like Uganda (UNFPA, 2015). Uganda has the youngest population in the world, with $48.47 \%$ of 44.27 million people being adolescents (World Population Review, 2019) (WHO, 2019).Being the largest and most energetic population makes young people's well-being an important determinant in a country's development agenda. Young people in their adolescent stage are very vulnerable and the sexual and reproductive health choices they make as they transition from childhood to adulthood determine a lot about their well-being and the development of the nation (WHO, 2010;UNFPA, 2012). The social and health choices adolescents make are largely influenced by the people with authority including religious leaders, faith based organizations, parents and governments in their community (Chitando, et al., 2019).

Globally, African communities value religious beliefs and consequently respect views from their religious leaders (Heward-Mills, et al., 2018). Religious leaders are authority figures who have access to all people: children, adolescents, young adults, the middle aged, and the elderly in African settings (Chitando, et al., 2019). They are important sources of guidance and influence in all aspects of life: the social, economic and political sector and Adolescent Sexual Reproductive Health (SRH)(Heward-Mills, et al., 2018;Mbote, et al., 2016 andChitando, et al., 2019). In this regard, religious leaders play a key role in guiding the adolescents on the sexual and reproductive health choices they make as they grow into adulthood (Stawsk, 2012). Therefore, religious leaders' understanding, perspectives and teachings are central in influencing the Adolescents Sexual Reproductive Health and Rights (ASRHR).

Generally, there is a challenge of harmonizing religious beliefs and the demands for reproductive health and rights of adolescents. On one side, several secular movements like the (UNFPA, 2014), Save the Children are promoting right-based interventions to improve access to sexual and reproductive health information and services (Chitando, et al., 2019). These include, among others, promoting access to comprehensive sexuality education; services to prevent, diagnose and treat Sexually Transmitted Infections (STIs); counselling on family planning and empowering young people to know and exercise their rights. On the contrary, religion teaches that sexual activity should not be discussed with those who are not ready for marriage because it will encourage them to have sex (Chitando, et al., 2019). This belief is against the concept of comprehensive sexuality education and inhibits access to sexual and reproductive health information 
and services to young adolescents. Most religious leaders feel that providing young adolescents with the means to have 'safe sex' is a way of encouraging them to have sex outside marriage, which is against their beliefs (Stawsk, 2012). While some religions accept the need for some form of family planning, for instance the Anglican church, many still discourage their followers from using modern family planning methods (Ngilangwa, et al., 2016;Adedini, et al., 2018).

Relatedly, religious leaders' roles can influence individual, social and structural factors which can directly determine the status of ASRHR. Individual factors such as knowledge and level of awareness on ASRH can lead to informed decisions on ASRHR as well as peer to peer promotion of ASRHR; social factors such as leadership support and information equity will result into social cohesion and sense of ownership leading to collective self-efficacy which facilitates ASRHR; and structural factors such as the capacity of religious leaders to advocate for laws and policies supportive of ASRH rights, can as well have an influence on the impact of community empowerment and engagement in ASRH(Ngilangwa, et al., 2016;Adedini, et al., 2018 and Stawsk, 2012).

To effectively promote adolescent sexual and reproductive health and rights, there is need to engage influential community members including parents and religious leaders (Santhya and Jejeebhoy, 2015). Research by the World Health organization showed that the most effective interventions for reaching young people are those that engaged community and religious leaders in promoting health among the young people (Ngilangwa, et al., 2016). However, the role of religious leaders in promoting adolescent sexual and reproductive health rights is not very clear and limited studies have been conducted in this regard.

Therefore, the current study seeks to explore the role of religious leaders in Iganga Municipality, Iganga District, Uganda in promoting ASRHR in order to generate evidence that can guide on the involvement of religious leaders in improving adolescent health.

\subsection{General objective}

The general objective was to assess the role of religious leaders in promoting Adolescent Sexual Reproductive Health and Rights (ASRHR) in Iganga Municipality.

\subsection{Specific objectives}

The study had the following specific objectives;

1) To examine the perceptions and attitudes of religious leaders towards promotion of adolescent sexual reproductive health and rights in Iganga Municipality by June 2020.

2) To examine the influences of leadership of religious leaders in the promotion of adolescent sexual reproductive health and rights in Iganga Municipality by June 2020.

3) To establish the impact of dialogue with religious leaders in the promotion of adolescent sexual reproductive health and rights in Iganga Municipality by June 2020.

4) To ascertain the effect of information sharing by religious leaders in the promotion of adolescent sexual reproductive health and rights in Iganga Municipality by June 2020.

\section{Methodology}

\subsection{Study design}

The study utilized a purely qualitative Phenomenological design to examine theroles of religious leaders in promoting ASRHR.

\subsection{Study population}

The study population comprised of the religious leaders on one hand and adolescents on the other hand. The religious leaders included Parish Priests, Catechists, Curates and Lay Executives for the Catholic denomination, Bishops, Archdeacons, Reverends and Lay Readers for the Anglican denomination. Khadi, Imams and Sheiks were for the Moslem fraternity and Pastors for the Seventh Day Adventists and the Pentecostals. Adolescents were from the respective places of worship.

\subsection{Sample size}

The study employed a sample of 30 participants; of whom 25 were religious leaders of the various religious institutions while 5 participants were adolescents expected to benefit from the information shared by the religious leaders.

\subsection{Sampling technique}

The study participants were selected using purposive sampling- a non-probabilistic sampling technique that allows selection of participants on the condition/belief that these are the best providers of the information desired to answer the research questions. The researchers thus singled out only those religious leaders that were believed to have solid information about the phenomenon under inquiry.

\subsection{Data collection tools \& methods}

The study utilized face-to-face in-depth interviews with all the study participants. Face-to-face interviews were chosen since the inperson interaction allows for a naturalistic setting while investigating a social phenomenon. All interviews were audio tapped or recorded. Interview guides as a data collection instrument with open ended questions were used. This enabled the researcher to generate an in depth understanding of the role of respondents in promoting adolescents sexual and reproductive health rights. 


\subsection{Quality controls}

Quality controls were taken care of. Prior to data collection, questions were developed. Translations and back translations of the tool was made, pre-tested amongst a similar sample population but in a different location. Triangulation of methods was done. In-depth interviews were tape recorded as well as field notes for each respondent. Member checks were done.

\subsection{Ethical considerations}

Participation in the study was voluntary and informed consents were sought from the respondents. The principle of confidentiality was adhered to and ethical approval was sought.

\section{Results}

\subsection{Background characteristics of respondents}

There were 30 participants ( 25 religious leaders and 5adolescents). Of the religious leaders, the average age was 44 years and included 21 males and 4 females. Apart from the 6 (six) religious leaders from the Catholic Church (priest and Nuns), the rest were officially married. They had served their respective institutions for at least 8 (eight) years and had Diplomas as the lowest educational level attained. For the adolescents; 3 were females and 2 were males aged between 15 - 19 years. They were from the different religious denominations; Catholic (2), Islam (1), Anglican (1) and SDA(1). Three of the adolescents were in school while the two were out of school. These characteristics thus put the religious leaders and adolescents in the best positions to give credible responses to the study. The respondents were coded 1-30.

\subsection{Perceptions and attitudes of religious leaders towards promotion of ASRHR}

\section{Theme 1: Mixed Perceptions and Attitudes}

The religious leaders appreciated that adolescence is a stage in the development of an individual that comes with changes in the body structure along with augmented body demands. They observed that as religious leaders, it is their responsibility to ensure that they tame these bodily demands through spiritual teachings and guide the adolescents through this stage until they can fully exercise their rights to sexual and reproductive health preferably, when they get married;

"[...] on the onset of puberty, adolescents usually ask themselves peculiar questions like; are all these organs that I possess functioning? ... are they doing their right work? Thus, it is at that moment that someone needs spiritual interventions such that one doesn't run off the mark; one doesn't become a slave to body demands. Accordingly, this is when religious leaders come in to create some sort of spiritual shock absorbers such that one can control himself as he goes through those physical demands of the body [...]", Respondent 1.

Additionally, religious leaders observed that ASRHR relates more to adolescents becoming promiscuous as a result of having too much freedom. They interpreted the "Rights" to mean freedom to do whatever they want. In relation to the above, they ascertained that ASRHR relates to training adolescents to be in position to have sex as was indicated by one of the respondents below;

"[...] when you talk about sexual reproductive health and rights, adolescents think you have given them freedom to do what they want, In our culture, sexual education was done by the girls' paternal aunties in preparation for marriage but when it's handled in a formal way with support from the donors, it brings in practices not desired in the country [...]" Respondent 3

Religious leaders observed that ASRHR concerns more with preparing the girl child for marriage. They were concerned however that focus has been on training the girl child while neglecting the boy child which may lead to disharmony in marriage as a result of boys not being prepared well.

"[...] our society base more on teaching and preparing the girl child for marriage while the boy child focuses on working to get money. ... but there is not much done for the boys [...]" Respondent 1.

Religious leaders also acknowledged that though they are in positions and spaces of influence, they are not knowledgeable enough to discuss issues concerning ASRHR. They revealed that they do not have any manual or guidelines to inform their involvement in matters regarding This is in line with the biblical doctrines which emphasize biblical teachings compared to any secular teachings.

"[...] most of us are not experts on the topic of ASRHR for example family planning and sexually transmitted Diseases (STDS) so, we sometimes get professional counselors to come and equip the adolescents with knowledge on ASRH because religious leaders will give only the biblical perspective [...]", Respondents 4.

In contrast from the above, however, some of the religious leaders acknowledged that adolescents are entitled to their sexual and reproductive health and rights. She argued that they have the freedom to exercise what they want although she acknowledged that they still need to be guided to go through this process well and it is the role of religious leaders to guide them.

"[...] as a religious group, we acknowledge that adolescents should have their rights to ASRH. We help them because we know that they are from different exposures... we know that perhaps those in tertiary institutions have even started courtship, so we guide them depending on their stage/age [...]" Respondent 5 
In agreement with the submission of religious leaders above, the respondent from another faith was very positive about ASRHR. He reasoned out that the youths constitute the highest percentage (70\%) in Uganda hence the need to invest in their health. He had this to say;

"[...] I, as a pastor and the church know that the youth total up to 70\% of the Ugandan population and it is our obligation as elders to consider the health of the youth in all aspects of their lives. When I hear about someone talking about the youth health rights, I feel happy..." Respondent 6

\title{
3.3. Influences of religious leaders in the promotion of ASRHR
}

\section{Theme 2: Influences and impacts of Religious leaders in Promoting ASRHR}

The results revealed that religious leaders' involvement in promotion of ASRHR impacts on behaviour of adolescents especially on the aspect of self - control and direct their focus towards getting to a point in time when they can freely exercise their rights. In this regard, one of the participants had the following to say;

"[...] when the medics think of physical health, the church thinks about the spiritual health because if somebody is grounded spiritually, the products of the spiritual growth and development is self-control, is bodily discipline, So, as the medical person thinks about an injection, religious leaders concentrate on spiritual healing which promotes self-control and patience [...]" Respondent 1

In a related manner, results revealed that involvement of religious leaders in promotion of ASRHR was influential and impactful as the leaders routinely encouraged adolescents to involve themselves in different activities. Some of the activities are; home-based chores, school extra-curricular activities and church related events. These avoid being idle and ending up attracting ungodly thoughts.

For example, a participant from the Catholic Church said that;

"[...] I try to encourage people to be productive because if the young got involved in productive work, then the rate of thinking about sexual activities or interaction with fellow adolescents reduces..." Respondent 7.

The results also revealed that religious leaders usually use their already existing structures to engage adolescents in discussions on ASRHR while going about their duties as religious leaders. For example, one of the leaders had this to say,

\section{"[...] we mostly meet, and we talk about a range of different topics as we go over our pastoral work. We make sure we integrate ASRHR messages with our biblical teachings..." Respondent 10}

It is also important to note that there is a dearth of evidence on associations between religious coping and sexual health. However, because religious beliefs often provide moral frameworks on sexuality, especially in countries like Uganda, adolescents are most likely to refer to religious teachings in order to make decisions about their sexual and reproductive health issues.

The religious leaders also never condoned sexual immorality although they admitted that it's natural and human for the adolescents to behave the way they do. It further emerged that religious leaders continuously engaged and offered guidance and direction to the adolescents although at times it requires collaboration between the religious leaders and health workers to articulate the salient issues.

\subsection{Impact of dialogue with religious leaders on the promotion of ASRHR}

\section{Theme3: Dialogues with Religious Leaders}

\section{Sub-theme (3a): Dialogues as Sources of Information for Religious Leaders}

Here, field results revealed that involving religious leaders in dialogue on ASRHR was vital because such avenues are sources of valuable information that do not only enables religious leaders execute the promotion of ASRHR effectively, but also gives them confidence and tailored information. These tailored information include real life challenges that adolescents go through. The dialogues then form the basis for tackling those challenges better when religious leaders meet the faithful. For example,

\begin{abstract}
"[...] yes, it is necessary, because it helps us as religious leaders to benefit from a variety of information that aids our work as we attempt to promote ASRHR in our communities. ... you know religious leaders are parents, teachers and at the same time counselors... so unless we have the right information packaged in a manner that doesn't distort the desired objective intended for the youths and adolescents, we can hardly engage them rightly.....this makes dialogue with key stakeholders more than necessary. Again, our teachings are usually derived from the bible and at times packaging it to suit some situations is a bit challenging hence dialogue helps us jump this huddle [...]" Respondent 5
\end{abstract}

Another participant observed that,

"[...] dialogue is very important because apart from parents, its only religious leaders who can easily be approached by adolescents for counsel. We are always available and observe confidentiality, so we need information to give to the adolescents [...]" Respondent 8

\section{Sub-theme (3b): Contributions of dialogues}

Results revealed that religious leaders were more empowered to hold discussions with adolescents about ASRHR after participating in dialogues that concern promotion of ASRHR. This is because they acquired the knowledge, skills, tools and materials they needed to fully support them engage the adolescents on matters relating to their sexual reproductive health and rights.

One respondent had this to say, 
"[...] as a religious leader, I feel more confident to talk to the adolescent girls and boys about SRHR after coming from a workshop prepared by organizations that provide ASRHR services and interventions because I will be equipped with the skills, messages and materials to use. [...]" Respondent 12

One participant observed that,

"[...] the religious leaders learn a lot of things in these dialogues which we dint know before which enrich our general outlook on the entire ASRHR programming [...]” Respondent 1

The study also pointed out that involving religious leaders in dialogues greatly influenced their attitudes towards adolescent sexual reproductive health and rights. This follows most of society's expectations that religious leaders focus on only religious and biblical teachings and leave matters concerning ASRHR to health professionals.

Another participant submitted that,

"[...] we want to show the adolescents that the issues of health are not only for medical personnel but it is something that concerns everyone, because when I, as a religious leader talks to the adolescent about health and the same adolescent hears the same message from a health worker and another community person maybe an agriculturalist, the adolescent will hold the credibility of the message with high esteem [...]" Respondent 7

Sub-theme (3c): Divergent Views

On another hand, whereas dialogues were held, some religious leaders hardly accorded any ASRHR to the adolescents. Instead, they routinely castigated fear to those that could probably contravene guidance from the respective leaders in relation to the provisions of the holy books as submitted;

"[...] Instead of telling adolescents the truth, we are ever threatening them... the bible calls upon the sinners to come closer to God but the pastors on the other hand have no kind words to those who have ever given birth outside wedlock, or those who have ever had an abortion calling them sinners... this scares people away instead of bringing them closer. [...]” Respondent 3

This is similar to three other respondents;

“[...] I agree [...]” Respondent 24

"[...] It is true [...]" Respondent 25

"[...] Yeah [...]" Respondent 20

\subsection{Effects of information sharing on promotion of ASRHR}

\section{Theme 4: Information Sharing}

\section{Sub-theme (4a): Categories of information Shared}

Results showed that religious leaders indeed passed on tailored health information especially those which concerns taming sexual desires as it is not the right time for the adolescents to exercise these rights. The leaders repeatedly cautioned the adolescents about avoiding indulging into premarital sex citing several dangers associated with it and the fact that it doesn't appease God. However, the message is passed on in a manner that threatens them to always avoid thinking about sexual activities although hope is created in their hearts that a time will come when they will have no limitations to their desires.

For example, one of the participants had this to say;

"[...] we tell them about the cons of engaging in early sex. So, we advise them while discouraging them from engaging in premarital sex. We tell them, however, that there is a right time to start having sex which is, the day of the honeymoon [...]" Respondent 1

However, another participant deviated from the former, submitting that it takes a variety of skills to get to terms with adolescents and youths and not simply threatening them into submission and adherence to instructions from elders.

\section{Sub-theme (4b): Impact of information Shared}

The study revealed that adolescents who received counselling from religious leaders take pride in it and share the same message with the rest of their peers. The information helps re-shape and focus adolescents' energy and behavior and eventually produce responsible citizens - lasting impacts.

"[...] that massage has made me be liked by very many people since I have inspired them. I chose to be an ambassador of responsible living whether am at church, school or within the community. I have helped a drug addict to completely stop abusing drugs by constantly encouraging him to practice responsible living which I leant from the religious leaders [...]" Respondent 26

Another adolescent asserted that continuing to respect information passed by religious leaders helps to change their attitude and focus their minds on things that matter. They also do cherish holy practices like fasting that helps them to self-reflect on the future and restore the virtue of patience and purity that are instrumental in shaping behavior.

Here he said the following,

"[...] now they encourage us to fast regularly because when you fast, you focus and meditate on the word of God which suffocates the bodily sexual fantasies and desires. The information I get from the mosque, has encouraged me and instilled fear in me [...]" said Respondent 27 
These views were similar for most of the adolescents interviewed in this study.

\section{Discussion}

\subsection{Perceptions and attitudes of religious leaders towards promotion of ASRHR}

Religious leaders who participated in the study precisely understood adolescents as people that anxiously desire to engage into sexual activities adding that adolescents should not be accorded have SRHR. It is something they don't qualify for until they get married. However, in recognition of the threats posed by adolescence, the religious leaders appreciate that adolescents need guidance about sexuality. Religious leaders have challenges addressing ASRHR especially the expectations from society which ascertain that religious leaders' primary role and focus should be preaching the word of God thus talking sexuality by a religious leader sounds like a taboo to the biggest part of the public. This is because society expects the parties traditionally charged with the responsibility of guiding adolescents about sexuality who are the aunties and uncles to adolescents to play a vital role in spearheading this subject in a more open manner.

Religious leaders also acknowledged that adolescents find themselves in a trap of sexualization and intimacy and eventually engage in unsafe sexual activities leading to consequences like unwanted pregnancies, STDs, school dropouts, early marriages and perhaps peasantry livelihoods. To address these consequences, religious leaders routinely roll out rehabilitation programs among which are establishing vocational training institutions that equip the affected adolescents with skills that can reshape the future of such people. The religious leaders are torn between balancing the demands of the sacred life and teaching with the pressures and demands that come from the secular life hence do post exposure interventions.

The results opine with Aaro, et al., (2014) who reasoned that the Ugandan culture limits parents to freely communicate with their adolescent children on sexuality because its regarded as a taboo. Relatedly, the findings are supported by Magezi (2016) who observed that most religious doctrines do not support some if not most of the demands of adolescents' sexual and reproductive rights. Accordingly, most religious leaders choose to go by uplifting what their doctrines ask of them, because they believe this is their primary role and that they should not disrespect their doctrines by promoting some aspects of ASRHR for example condom use among the adolescents and use of modern contraceptives. Promoting such ASRHR demands is perceived as downplaying their faith. The results are also in agreement with Muhwezi et al., (2015) reasoning that religious leaders may be hindered from talking to their congregations about sexuality and they leave such discussion for relatives such as aunties, just like it is widely known in Uganda that information and advice about sexuality should be given by paternal aunties. The results further agree with Anarfi et al., (2011) submitting that religious leaders perceive ASRHR services and information as not fit for adolescents, even though many young people, including those in Uganda are already engaging in premarital sex. They added that, while some religious followers found it important for religious leaders to advise youth about sexual and reproductive health matters, some participants thought that they do not expect religious people to openly talk about sexual matters.

\subsection{Influences of religious leaders in the promotion of ASRHR}

Generally, the existing literature shows that religious leaders have a protective and preventive influence regarding promotion of ASRHR. For instance, they focus more on discouraging young people from engaging in premarital sex rather than advising them to have safe sex by demanding and utilizing the available mechanisms like using condoms and embracing modern family planning.

It is evident from this study findings presented and accompanying scholarly works that religious leaders influence the promotion of ASRHR by calling upon the adolescents to exercise self-control (self - discipline) amidst the sexual desires and demands. This is preciously achieved through preaching to and healing the spirit which they believe convinces the mind and eventually the body to desist engaging into premarital sex. The religious leaders also strive to advocate and encourage productive engagement by the adolescents with intent to avoid redundancy which would lead them to harbor immoral or sexual thoughts. Thus, the adolescents are encouraged to take part in household chores like cleaning the house, school activities or church related activities such as cleaning the church compound, cleaning the church itself or joining the church choir.

Through use of all available platforms, religious leaders routinely remind adolescents about the ASRHR and use the word of God to preach to the youth and adolescents the dangers of sex before marriage and how sexual immorality is punishable by God. The religious leaders also continuously call for collective action by all stakeholders especially those in positions of responsibility especially health workers, political leaders or elders to always call the adolescents to order. The findings are in line withAdamczyk and Hayes (2012)who reasoned that regular attendance of religious activities and events as well as ceremonies by adolescents was associated with a lower risk of having had sex and having unprotected sex amongst young women but not young men although in particular the Hindus and Muslims were significantly less likely to report having had premarital sex than Christians and Jews

The findings are supported by van Reeuwijk and Nahar (2013) reasoning that an increasing number of adolescents demand for and are being involved in a number of SRHR programs that target them, which is a reflection of the fulfillment of adolescents' rights to health, but this as well improves effectiveness of interventions that target them. The results further revealed that this positive approach creates youth-adult partnerships where youths are strongly empowered to be active citizens who play a role in causing social change.

\subsection{Impact of dialogue with religious leaders in the promotion of ASRHR}

From the study findings, dialogues enhanced religious leaders' awareness of adolescent sexual reproductive health and rights by equipping them with relevant knowledge and skills. This in turn impacted on their attitudes towards adolescent sexual reproductive health and rights. However, some religious leaders did not accord any rights to the adolescents instead they castigated fear to the adolescents through the way they packaged the messages and communication. This way the religious leaders gained more knowledge and became well informed about the subject matter of ASRHR so they can address the adolescents with confidence and ease. It is a way of helping the religious leaders adjusts on some positions they hold about ASRHR and accept to live with SRH amongst the religious institutions. Therefore, the earlier they understood dealing with them confidently the better.

The above position is in agreement with Gumboh, (2017) saying that dialogues with religious leaders promoted open discussions on SRHR in places of worship like mosques and churches which helped in breaking social and religious barriers that hinder young people from realizing their sexual and reproductive health rights. 
The findings also agree with Save the Children, (2009) that witnessed the community rejection of ASRH communication materials that they had designed for adolescents in Bangladesh, until after they had involved the key stakeholders in the community including religious leaders that the program prospered. Further still, Kangaude, (2016) concurs asserting that some African societal norms tend to stigmatize adolescent sexual conduct, where by their sexual and reproductive health rights are constrained for example; some norms discourage their access to contraceptives and this therefore increases the risk of unwanted pregnancies and unsafe abortions which the adolescents are again blamed for.

\subsection{Effects of information sharing on promotion of ASRHR}

It is evident that religious leaders focus on the message of abstinence which contradicts reality since regardless of this message; a host majority of the adolescents are getting involved in unsafe premarital sexual activities leading to teenage pregnancies and the associated consequences. The position is held byMagezi (2016) in his case study report on the health work of the Salvation Army in East Africa, noting that religious leaders' participation in health largely focuses on uplifting the spiritual part of life and over looks what is happening adding that on account of this, some religious beliefs are strongly against promotion of ASRHR.

On a positive note however, it is worth submitting that adolescents who hid to the advice they got from their religious leaders in form of information, lived a responsible life and became champions/ambassadors of positive change and are respected and admired by their fellow peers. They stayed free from sexual immorality and at times guided their peers on how to leave responsibly.

This is in line with Magezi, (2016), comfirming that religious doctrines often deny adolescents their sexual reproductive health rights and religious leaders find it challenging to uphold the sacredness of religion, while promoting the adolescent sexual and reproductive health rights.

This position is supported by Magezi, (2016) ascertaining that most religious settings abide with the sex abstinence message and tend to promote this more often as opposed to encouraging methods such as condom use for safe sex or use of contraceptives. The results also agree with Agha (2014), who found that peer-led counseling as well as parent-based education significantly improved the knowledge of the participants on SRHR. Relatedly, Gold et al., (2010) reasoned that given that most religions advocate for abstinence before marriage, it is not surprising to find that those female adolescents with higher levels of religiosity were less likely to be sexually active.

\section{Conclusion}

Religious leaders greatly contribute to the promotion of ASRHR by enhancing information sharing regarding ASRHR although this information is rooted in spiritual healing and abstinence. Dialogues with religious leaders enhance their awareness on ASRHR and gives them confidence to address the same. They have both protective and preventive influences regarding ASRHR. However, religious leaders perceive ASRHR to imply sexual immorality and thus accord no rights to the adolescents until they are married off.

\section{Acknowledgement}

The authors acknowledge and appreciate the support from the religious leaders and adolescents that participated in the study. They made the study a success. We also acknowledge Uganda Martyr's University, faculty of Health Sciences for the ultimate support towards completing this study.

\section{Conflict of interest}

We, the authors, declare no conflict of interest, of any kind.

\section{Consent for publication}

The authors do consent for publication of this work guided by the terms and conditions of the journal

\section{External funding}

There was no external funding for this study.

\section{References}

[1] Aarø, L.E., Mathews, C., Kaaya, S., Katahoire, A.R., Onya, H., Abraham, C., Klepp, K.I., Wubs, A., Eggers, S.M. and De Vries, H., 2014. Promoting sexual and reproductive health among adolescents in southern and eastern Africa (PREPARE): project design and conceptual framework. BMC Public Health, 14(1), p.54.https://doi.org/10.1186/1471-2458-14-54.

[2] Adamczyk, A. and Hayes, B.E., 2012. Religion and sexual behaviors: Understanding the influence of Islamic cultures and religious affiliation for explaining sex outside of marriage. American Sociological Review, 77(5), pp.723-746.https://doi.org/10.1177/0003122412458672.

[3] Adedini, S.A., Babalola, S., Ibeawuchi, C., Omotoso, O., Akiode, A. and Odeku, M. 2018. Role of religious leaders in promoting contraceptive use in Nigeria: evidence from the Nigerian Urban Reproductive Health Initiative. Global Health: Science and Practice,6(3), pp.500514.https://doi.org/10.9745/GHSP-D-18-00135.

[4] Agha, L., 2014. The effects of health information technology on the costs and quality of medical care. Journal of health economics, 34, pp.1930.https://doi.org/10.1016/j.jhealeco.2013.12.005.

[5] Anarfi, J. K. and Owusu, A.Y., 2011. The making of a sexual being in Ghana: The state, religion and the influence of society as agents of sexual socialization. Sexuality \& Culture, 15(1), pp.1-18.https://doi.org/10.1007/s12119-010-9078-6.

[6] Anshel, M.H. and Smith, M., 2014. The role of religious leaders in promoting healthy habits in religious institutions. Journal of religion and health, 53(4), pp.1046-1059.https://doi.org/10.1007/s10943-013-9702-5.

[7] Chitando, E., Ragies, G. \& Abednicho, N, 2019.Religious Leaders'Handbook on Adolescent Sexual \&Reproductive Health and Rights. 
[8] Gold, M., et al. (2010). "Associations between Religiosity and Sexual and Contraceptive Behaviors." Journal of pediatric and adolescent gynecology 23: 290-297.https://doi.org/10.1016/j.jpag.2010.02.012.

[9] GUMBOH, B. 2017. Approaches to effective engagement of religious leaders on Sexual and reproductive health for youth

[10] Heward-Mills, N.L., Atuhaire, C., Spoors, C., Pemunta, N.V., Priebe, G. and Cumber, S.N., 2018. The role of faith leaders in influencing health behaviour: a qualitative exploration on the views of Black African Christians in Leeds, United Kingdom. The Pan African Medical Journal, 30.https://doi.org/10.11604/pamj.2018.30.199.15656.

[11] Kangaude, G., 2016. Enhancing the role of health professionals in the advancement of adolescent sexual health and rights in Africa. International Journal of Gynecology \& Obstetrics, 132(1), pp.105-108.https://doi.org/10.1016/j.ijgo.2015.10.001.

[12] Magezi, V., 2016. A proposition for an integrated church and community intervention to adolescent and youth sexual reproductive health challenges. HTS Theological Studies, 72(2), pp.1-9.https://doi.org/10.4102/hts.v72i2.3832.

[13] Mbote, D.K., Sandfort, T.G., Waweru, E. and Zapfel, A., 2018. Kenyan religious leaders' views on same-sex sexuality and gender nonconformity: Religious freedom versus constitutional rights. The Journal of Sex Research, 55(4-5), pp.630-641.https://doi.org/10.1080/00224499.2016.1255702.

[14] Muhwezi, W.W., Katahoire, A.R., Banura, C., Mugooda, H., Kwesiga, D., Bastien, S. and Klepp, K.I., 2015. Perceptions and experiences of adolescents, parents and school administrators regarding adolescent-parent communication on sexual and reproductive health issues in urban and rural Uganda. Reproductive Health, 12(1), p.110.https://doi.org/10.1186/s12978-015-0099-3.

[15] Ngilangwa, D.P., Rajesh, S., Kawala, M., Mbeba, R., Sambili, B., Mkuwa, S., Noronha, R., Meremo, A.J. and Nyagero, J., 2016. Accessibility to sexual and reproductive health and rights education among marginalized youth in selected districts of Tanzania. The Pan African Medical Journal, 25(Suppl 2).https://doi.org/10.11604/pamj.supp.2016.25.2.10922.

[16] Santhya, K.G. and Jejeebhoy, S.J., 2015. Sexual and reproductive health and rights of adolescent girls: Evidence from low-and middle-income countries. Global public health, 10(2), pp.189-221.https://doi.org/10.1080/17441692.2014.986169.

[17] Stawsk, H., 2012. Enhancing Sexual andReproductive Health andWell-Being of Young People:Building Common Groundbetween the United Nations andFaith-Based Development Partners.

[18] Tripathi, A.D., Mishra, R., Maurya, K.K., Singh, R.B. and Wilson, D.W., 2019. Estimates for world population and global food availability for global health. In The role of functional food security in global health (pp. 3-24). Academic Press.https://doi.org/10.1016/B978-0-12-813148$0.00001-3$.

[19] UNFPA. 2012. Ageing in the twenty-first century: A celebration and a challenge. London and New York: Author

[20] UNFPA. 2014. Implementation of the International and Regional Human Rights Framework for the Elimination of Female Genital Mutilation. New York: Author

[21] UNFPA. 2015. Annual Report, 2015: Delivering a world where every pregnancy is wanted every childbirth is safe and every young person's potential is fulfilled.

[22] Van-Reeuwijk, M. and Nahar, P., 2013. The importance of a positive approach to sexuality in sexual health programmes for unmarried adolescents in Bangladesh. Reproductive Health Matters, 21(41), pp.69-77.https://doi.org/10.1016/S0968-8080(13)41694-4.

[23] World Health Organization [WHO]. 2010. World health statistics 2010. Geneva: Author.

[24] World Health Organization, 2019. INSPIRE handbook: action for implementing the seven strategies for ending violence against children. Geneva: Author. 